\title{
Optimization of College English Acquisition on the Basis of Mind-Map and Meta-Cognitive Learning Strategies
}

\author{
Miao Huang \\ Yantai Nanshan University, Longkou, China \\ Email: irenehashida@126.com
}

Received 31 May 2016; accepted 17 June 2016; published 24 June 2016

Copyright (C) 2016 by author and OALib.

This work is licensed under the Creative Commons Attribution International License (CC BY). http://creativecommons.org/licenses/by/4.0/

(c) (i) Open Access

\begin{abstract}
In modern society, both science and technology are developing at an unprecedented rate, which need more talents. The key of talent training includes, on the one hand, professional knowledge and skills and on the other hand, the ability of thinking and autonomic learning. As an effective tool of thinking, mind-map can develop human potential and the students' thinking ability greatly. Mind-map is made up of lines, symbols, text, color and graphics elements. One can visualize the storage, organization, arrangement, study, and review and memorize information by applying this effective means of thinking. It is based on the related way of thinking style that one can construct his own knowledge system. At the same time, meta-cognition is people's perception of their own cognitive activities, which includes meta-cognitive knowledge (thinking about thinking), metacognitive experience (selecting and using strategies), and meta-cognitive monitoring strategy. Meta-cognitive learning strategies are playing an important and essential role in students' autonomic learning. Based on meta-cognitive learning strategies and mind-map, the author takes college English teaching and learning process of non-English major students in Yantai Nanshan University as the research objective, explores the optimization of college English teaching and learning pattern and provides references for college teachers home and abroad.
\end{abstract}

\section{Keywords}

College English Education, Mind-Map, Meta-Cognitive Learning Strategies

Subject Areas: Education, Linguistics

\section{Introduction}

Just as the famous saying goes, "Live and Learn”, which refers to the fact that education is a long-term process, 
the final goal of education is to train talents who can learn effectively and independently. As the advanced stage of school education, college education plays an important role in the acquisition of knowledge and skills and cultivation of abilities in thinking and autonomous learning. Meta-cognition is the senior control system of the cognition process, which is unavoidable in any specific cognitive field. As for English learning, it is, as a matter of fact, the course of information processing, which is unavoidably influenced by cognitive factors. Meanwhile, assisted by lines, symbols, text, color and graphics elements, mind-map visualizes the result of abstract thinking. It is based on the related way of thinking style that one can construct his knowledge system, which is the essential part of autonomic learning. So far, mind-mapping is widely used in a variety of fields and researches on its application in language acquisition, especially college English teaching and learning, are of great value.

Therefore, based on meta-cognitive learning strategies and mind-map, the author takes college English teaching and learning process of non-English major students in Yantai Nanshan University as the research objective, explores the optimization of college English teaching and learning pattern and provides references for college English teachers home and abroad. Generally speaking, the essay includes the following three parts: First, literary review on mind-map theory and meta-cognitive learning theory, especially their application in language acquisition; Second, survey and analysis on current situation in college English teaching and learning process for non-English major students in Yantai Nanshan University; Third, the optimization of college English teaching mode based on the former two theories.

\section{Mind-Map Theory and Its Application in Language Acquisition}

The term “mind-map” was first popularized by British popular psychology author Tony Buzan [1]. A mind-map is a diagram used to visually organize information. It is often created around a single concept, drawn as an image in the center of a blank page, to which associated representations of ideas such as images, words and parts of words. Major ideas are connected directly to the central concept, and other ideas branch out from these major ideas. Mind-map can be used to generate, visualize, structure, and classify ideas, and as an aid to studying and organizing information, solving problems, making decision, and writing. Mind-map have many applications in personal, family, educational, and business situations, including note-taking, brainstorming, summarizing, or sorting out a complicated idea.

Currently, researches on Mind-map mainly focus on the following four aspects: Firstly, the effectiveness. Cunningham [2] conducted a user study in which eighty percent students regard that "mind-map help them understand concepts and ideas in science". Other studies also report positive effects through the use of mind-map. Farrand, Hussain, and Hennessy [3] found that Mind-map had limited, but significant, impact on memory recall in undergraduate students; Secondly, researches on features of mind-map. Beel and Langer [4] conducted a comprehensive analysis of the content of mind-map, the result of which showed that between different mindmap applications, significant differences exist related to how users create mind maps; Thirdly, researches on automatic creating of mind-map. There have been some attempts to create mind maps automatically. Brucks and Schommer [5] created mind maps automatically from full-text streams. Rothenberger et al. [6] extracted the main story of a text and presented it as mind map. And there is a patent about automatically creating sub-topics in mind maps; Finally, Pen and paper vs. computer. There are studies analyzing whether electronic mind-mapping or pen based mind mapping is more effective.

In conclusion, mind-map is an effective method in various fields and it will bring breakthrough in language learning and teaching, especially in level of college.

\section{Meta-Cognition}

The term meta-cognition literally means cognition about cognition, or more informally, thinking about thinking. Meta-cognition is defined as knowledge about cognition and control of cognition. Meta-cognition also thinks about one's won thinking process such as study skills, memory capabilities, and the ability to monitor learning. Meta-cognition knowledge is about our own cognitive processes and our understanding of how to regulate those processes to maximize learning.

So far, in the field of education and learning, meta-cognition can be interpreted from three aspects: metacognitive knowledge, meta-cognitive experience, monitoring strategies. Meta-cognitive knowledge refers to cognition on the learning target; meta-cognitive experience refers to the emotional experience, including the feelings, judgment, and prediction in the course of cognition; monitoring strategies refers to the control and ad- 
justment in the course of cognition to maximize the effect of learning. In the specific cognitive activities, the three factors are simultaneous and interrelated. Meta-cognitive knowledge is the base; meta-cognitive experience can enrich the former and meanwhile adjust the application of meta-cognitive monitoring strategies. They all promote the course of cognitive activities.

\section{Current Situation of College English Acquisition}

Foreign language teaching is a complicated and systematic project, including a great variety of components, for example, professors, students, teaching mode, teaching manual, test and assessment. Based on different educational theories, the mode of college English teaching can roughly be divided into three categories, to be specific, teacher-centered teaching mode, student-centered interactive teaching mode, integrated teaching mode. In addition, as the rapid development of modern science and technology, especially the widespread of Internet, scientific educational technologies has entered and are playing an important role in college English teaching. Not only are computers and projectors used in exhibiting teaching materials, but also the whole course of teaching. What's more, the students can make full use of their spare time, learning by themselves, which is, on the one hand, corresponding with the modern concept of learning and teaching; on the other hand, emphasizing the importance of autonomic learning ability and skills.

In order to know the current situation of college English teaching and learning, the authors takes non-English major students in Yantai Nanshan University as target research group, surveying their puzzles and difficulties in the course of English learning. Through communicating with these students, the author found the existence of some inevitable problems. First, some students say "I know English is really important for the study of professional knowledge and for my future career. However, I feel frustrated by the fact that I cannot master it even though I've learned it for at least ten years"; Others say "I cannot communicate with native speakers freely. The more I want to say, the less I can say our". Both indicate the embarrassing situation of College English teaching - teachers and students work hard on English teaching and learning, while the result of learning is not satisfying; Secondly, College English teaching is deeply affected by intellectualism. All teaching factors are centered with knowledge itself, including the presenting of teaching content, teaching method, and teaching mode so on and so forth. At the same time, students' non-intellectual factors, such as attitude, views on learning, are neglected consciously and unconsciously; Finally, simplicity and stylization also block the interaction between teachers and students.

To conclude, all factors mentioned above affect the effect of college English teaching. In other word, introducing a teaching and learning method based on advanced educational concepts are essential, and the introducing of mind-map and meta-cognitive learning strategies is a favorable attempt.

\section{Optimization of College English Acquisition on Basis of Mind-Map and Meta-Cognitive Learning Strategies}

\subsection{College English Acquisition from the Aspect of Planning Strategy and Mind-Map}

Plan strategy refers to learners' planning of learning objectives, content, time, schedule, learning strategy, so on and so forth before the start of learning activities. In autonomous learning, in the first place, students should make scientific plan and acquire corresponding executive capacity. To be specific, to allow learners to arrange learning content according to their own learning process; In the second place, students should be able to undertake corresponding learning responsibility; What's more, teachers should assist learners to further foster and develop their independent learning strategies, and give full play of their enthusiasm and initiative. However, the fact is that in the process of autonomous learning, some learners have acquired meta-cognitive learning strategies and can apply these strategies in learning. For example, before the start of learning activities, they can make detailed schedule on learning content, timing, and target tasks. By contrary, there are still quite a few learners who learn English passively. That is, they can only carry out the learning process under teachers' instructions without individual initiatives.

For any language acquisition activity, learners are always the main body of learning. Learners' initiative should be fully exerted with the purpose of enhancing the application of planning strategy in the process of College English teaching. Generally speaking, it includes the following measures: On the one hand, to establish a correct concept on autonomous learning and realize creative learning, which is the premise of all learning activi- 
ties; On the other hand, in order to activate learners' internal learning motivation, the purpose and value of learning should be emphasized and external rewards should also be desalinated; To sum up, by using above methods to improve students' planning strategy, the effect of learning can be improved greatly.

\subsection{College English Acquisition from the Aspect of Monitoring Strategy and Mind-Map}

Monitoring strategy refers to the learners' active monitoring process in their learning behavior. Thus, on the basis of reflections on the monitoring result, learners can constantly adjust their learning strategies, so as to ensure the achievement of learning goals. At present, with the open network environment, network information resources and the problem of over-abundant information aroused people's concern. Also in the course of College English learning, students are facing more kinds of information and various points of view on learning. Being lack of teachers' guidance, supervision and management functions, students feel confused, and they need further guidance and management. However, the fact is that vast majority of students now excessively depend on external forces, such as the teacher's guidance and constraint, although to a certain extent, they have acquired an independent way of learning. In another word, they haven't established a strong sense of independent learning ability to solve problems.

\subsection{College English Acquisition from the Aspect of Assessment Strategy and Mind-Mapping}

Evaluation strategy, also called assessment strategy, refers that students can reflect and evaluate their own cognitive activities and strategies according to the relevant evaluation standards at the end of the learning activities. By applying assessment strategy, learners can timely detect problems in the process of learning, and correct the deficiencies. As the indispensable link of learning process, evaluation mechanism can ensure the learning effect and improve the efficiency of learning. Therefore, under current network background and in the process of College English teaching, students should be aware of the evaluation of online autonomous learning. The reason is that, on the one hand, learners' learning effect is not satisfying, and they are weak in self-control. For example, they fail to finish the learning tasks, achieve learning goals, and make it impossible to make effective learning feedback and evaluation; On the other hand, the learning evaluation of this cognitive process itself is seriously enough. Therefore, teachers should guide students to form their own learning process evaluation, to combine knowledge evaluation and emotional feedback evaluation together, and to focus on the dynamic evaluation and process evaluation. In this way, learners can truly understand their own deficiency in the learning process, be able to get timely feedback and correction, and finally promote autonomous learning effect.

\section{Conclusion}

So far, the research on college English teaching and learning is developing and deepening, which has achieved fruitful results. However, those researches mainly focus on the theoretical aspect, while the practical exploration and attempt are not enough. There are still some questions. For example, how to make students acquire the ability of learning independently and effectively? How to foster the ability of creative thinking? Mind-map and meta-cognitive learning strategy should be one possible answer. In this essay, under the guidance of meta-cognition learning strategies, the author uses the practical method of mind-map to explore the optimization of college English teaching, and hopes to provide direct and effective references for both English teaching and learning. These two methods conform the scientific rules of cognition and thinking, which are vital to the improvement of college English learning and teaching. What's more, as an international tool for communication, English is playing a more important role in globalization. Therefore, learning and finally mastering the language has been of great necessity for college students, so does the exploration on improvement of teaching and learning effect and efficiency. This is, actually, the common issue for all non-native English speakers. Certainly, there are limitations in the essay: for example, the abilities and skills of mind-map and meta-cognitive learning strategies need to be fostered continuously and for quite a long time; skills of mind-map targeting college English learning and teaching need further study. Both of them will be discussed in further study.

\section{References}

[1] Buzan, T. and Buzan, B. (1993) The Mind Map Book: How to Use the Radiant Thinking to Maximize Your Brain’s Untapped Potential. Penguin Book Ltd., London. 
[2] Cunningham, G. (2005) Mindmapping: Its Effects on Student Achievement in High School Biology. Ph.D. Thesis, The University of Texas, Austin.

[3] Farrand, P., Hussain, F. and Hennessy, E. (2002) The Efficacy of the Mindmap Study Technique. Medical Education, 36, 426-431. http://dx.doi.org/10.1046/j.1365-2923.2002.01205.x

[4] Beel, J. and Langer, S. (2011) An Exploratory Analysis of Mind Maps. Proceedings of the $11^{\text {th }}$ ACM Symposium on Document Engineering, 81-84. http://dx.doi.org/10.1145/2034691.2034709

[5] Brucks, C. and Schommer, C. (2008) Assembling Actor-Based Mind-Maps from Text Stream. arXiv:0810.4616 [cs.CL]

[6] Rothenberger, T., Oez, S., Tahirovic, E. and Schommer, C. (2008) Figuring out Actors in Text Streams: Using Collocations to Establish Incremental Mind-Maps. arXiv:0803.2856 [cs.CL]

\section{Warmly welcome your paper submission to OALib Journal!}

- Publication on a daily basis

- 9 subject areas of science, technology and medicine

- Fair and rigorous peer-review system

- Fast publication process

- Article promotion in various social networking sites (LinkedIn, Facebook, Twitter, etc.)

- Widely-targeted and multidisciplinary audience to read your research

Submit Your Paper Online: Click Here to Submit

Contact Us: service@oalib.com 